\title{
Wasting illness as a disorder of body weight regulation
}

\author{
BY MICHAEL W. SCHWARTZ ${ }^{1}$, RANDY J. SEELEY ${ }^{2}$ AND STEPHEN C. WOODS ${ }^{2}$
}

Departments of ${ }^{1}$ Medicine and ${ }^{2}$ Psychology, University of Washington, Harborview Medical Center and VA Puget Sound Health Care System, Seattle, WA 98108, USA

Despite marked variation in daily energy intake and energy expenditure, body weight and body fat stores remain relatively stable over time in normal individuals. Thus, mismatches between energy intake and expenditure over the short term appear to be corrected over longer time intervals (Keesey \& Powley, 1986; Leibel et al. 1995). This key observation suggested to early investigators that physiological processes must exist to maintain stability in the total amount of fuel stored as adipose tissue (Kennedy, 1953). The importance of this regulation is emphasized by the observation that in order for a $70 \mathrm{~kg}$ man to avoid changing his weight by $10 \mathrm{~kg}$ over a 10 -year period, energy intake and energy expenditure must be matched with at least $98 \%$ precision. Because normal individuals defend a regulated level of body adiposity with remarkable rigor, therefore, weight loss resulting from voluntary energy restriction (e.g. by dieting) is usually regained over time (Drenick \& Johnson, 1978; Garner \& Wooley, 1991).

The concept that adipose stores are subject to homeostatic regulation provides an important context within which to consider the pathogenesis of wasting illness. The sustained weight loss commonly encountered among patients with diseases such as acquired immune deficiency syndrome or malignancy is a major contributor to the morbidity and mortality of these diseases (Grunfeld \& Feingold, 1992). The cause of this weight loss is often multi-factorial, with inanition, malabsorption, increased energy expenditure, disturbances in the ability to store fat, and anorexia each potentially playing a role. However, several studies have confirmed that the failure to consume sufficient energy to meet ongoing energy demands is a major factor in wasting illness (Grunfeld \& Feingold, 1992). Since normal individuals accomplish this with great precision, two important questions arise regarding the pathogenesis of wasting illness. First, what factors contribute to reduced food intake? Second, why does weight loss in wasting illness fail to activate the compensatory response that is so robust in normal subjects? Insights into the answers to both questions have emerged from recent advances in our understanding of the physiology of body weight regulation.

\section{NEGATIVE FEEDBACK CONTROL OF ADIPOSITY}

The concept that circulating signals generated in proportion to body fat stores influence appetite and food intake was first proposed by Kennedy (1953). According to his model, changes in energy balance (the difference between energy consumed and energy expended) sufficient to alter body fat stores are signalled via one or more circulating factors that act in the brain to elicit compensatory changes in food intake. Thus, diet-induced weight loss was predicted to lower the circulating level of signals that inhibit food intake, resulting in a stimulation of feeding behaviour until lost weight is regained. The studies of Coleman (1973), performed about 20 years later, used two different models of genetic obesity in mice to provide evidence that such circulating signals must exist. Working with mice with an autosomal recessive mutation of the obese $(o b)$ gene, Coleman (1973) deduced that the absence of a circulating signal that inhibits food intake led the animals to over-eat and 
develop a severe form of obesity. Autosomal mutation of another gene locus, the diabetes $(d b)$ gene, resulted in a similar form of obesity that Coleman (1973) suggested was due to the inability to respond to these circulating signals. Thus, Coleman (1973) proposed that the $o b$ gene encodes a hormone that causes anorexia, whereas the $d b$ gene encodes the receptor for this hormone.

Studies performed over the past 2 years have confirmed the model proposed by Coleman (1973) nearly 25 years ago. A major breakthrough was provided by Friedman's group (Zhang et al. 1994) with the cloning of the $o b$ gene. This work demonstrated that the $o b$ gene encodes a polypeptide hormone synthesized by and secreted from fat cells, and also identified the specific mutation of the $o b$ gene that causes obesity in the $a b / o b$ mouse. The hormonal product of the $o b$ gene, termed 'leptin' (Greek for 'thin') is now known to be secreted into the circulation of both animals and man in proportion to the level of fat stores (Frederich et al. 1995; Considine et al. 1996; Rosenbaum et al. 1996). Moreover, correction of leptin deficiency in the $o b / o b$ mouse causes a marked reduction of food intake and a normalization of the obesity syndrome (Campfield et al. 1995; Halaas et al. 1995; Pelleymounter et al. 1995). Subsequent studies determined that the $d b$ mutation resides in the gene encoding the leptin receptor (Chua et al. 1996; Lee et al. 1996), confirming Coleman's (1973) hypothesis that obesity in the $d b / d b$ mouse is caused by resistance to the hormone encoded by the $o b$ gene. Thus, both leptin deficiency (in the $o b / o b$ mouse) and leptin resistance (in the $d b / d b$ mouse) lead to severe obesity in mice, strongly implicating leptin as a negative feedback signal critical to the normal control of food intake and body weight.

In addition to leptin, the hormone insulin, best known for its role in the control of blood glucose, also appears to function in the negative feedback control of body adiposity (Woods et al. 1985). While insulin is secreted from the endocrine pancreas, rather than the fat cell, it circulates in concentrations proportional to body fat stores, as does leptin (Bagdade et al. 1967). Like leptin, insulin administration directly into the brain inhibits food intake and promotes weight loss (Woods et al. 1985), and receptors for both insulin and leptin are expressed in key hypothalamic areas involved in food intake control and energy homeostasis (Schwartz et al. 1992a, 1996; Mercer et al. 1996). The hypothesis that insulin and leptin interact in brain areas involved in the control of food intake and energy expenditure is, therefore, being actively studied.

\section{HYPOTHALAMIC MECHANISMS INVOLVED IN BODY-WEIGHT REGULATION}

An emerging concept explaining how circulating signals such as insulin and leptin control food intake and body weight proposes that these hormones act on discrete hypothalamic pathways (Kaiyala et al. 1995; Schwartz et al. 1996). Such 'hypothalamic effector pathways', when activated, have potent and sustained effects on energy balance. One group of these pathways is composed of neural circuits that stimulate food intake and promote weight gain, and their activity appears to be inhibited by negative feedback from insulin and leptin. A second family of effector pathways exerts the opposite effect (e.g. reduced food intake and increased energy expenditure, thereby promoting weight loss), and these are proposed to be stimulated by circulating negative feedback signals. The former effector pathways are predominantly 'anabolic', since they promote an increase in energy content of the body, and the latter are 'catabolic', since they promote the dissipation of energy from the body. The proposed interactions between negative feedback signals and hypothalamic effector pathways in the control of food intake is illustrated in Fig. 1. 
Effects of NPY and CRH on energy homeostasis

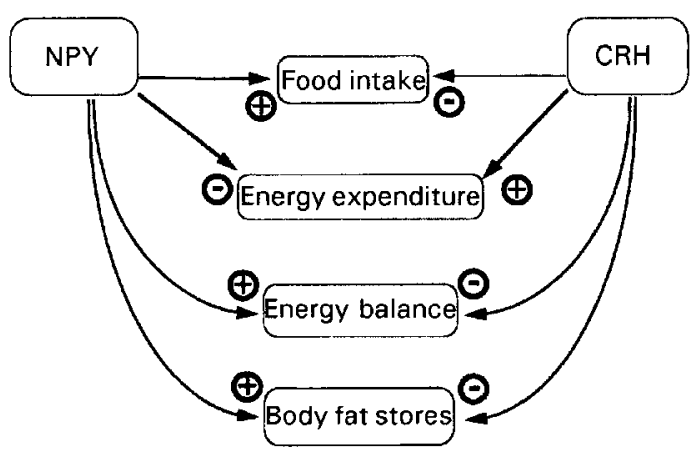

Fig. 1. Schematic illustration of opposing actions of neuropeptide Y (NPY) and corticotrophin-releasing hormone (CRH) on determinants of energy balance (the difference between energy intake and expenditure). NPY acts in the hypothalamus to increase food intake while reducing energy expenditure, a combination that promotes weight gain. CRH causes anorexia and increases energy expenditure, thereby promoting weight loss.

To date, two neuropeptide-containing pathways have been identified in the hypothalamus which are strongly implicated as central effector systems. The hypothalamic pathway utilizing neuropeptide Y (NPY) as a transmitter is a representative of the anabolic effector systems, whereas corticotrophin-releasing hormone (CRH) is representative of the catabolic effector pathways (Kaiyala et al. 1995). Following injection directly into the brain, both NPY (Stanley, 1993) and CRH (Rothwell, 1989) expert potent and sustained effects on food intake and body weight. NPY stimulates food intake and reduces energy expenditure, thereby promoting the rapid accumulation of fuel stored in the form of adipose tissue (Clark et al. 1984; O'Donohue et al. 1985; Stanley et al. 1986; Stanley, 1993; Zarjevski et al. 1993). CRH, on the other hand, causes an anorectic response which is coupled with an increase in energy expenditure, thereby eliciting sustained weight loss with repeated central administration (Krahn \& Gosnell, 1988; Rothwell, 1989). Thus, both NPY and $\mathrm{CRH}$ elicit multi-faceted effects on the central control of energy balance, and these effects are diametrically opposed to one another.

While their pharmacological profiles suggest a physiological role for these peptides in the control of food intake and body weight, an even more compelling argument derives from the study of factors regulating NPY and CRH production and release in the hypothalamus. Although NPY is expressed abundantly throughout the brain, the primary site of hypothalamic NPY biosynthesis is within the arcuate nucleus (O'Donohue et al. 1985; Stanley, 1993). These NPY-containing neuronal cell bodies project to the paraventricular nucleus (PVN), an area which is highly sensitive to the effect of NPY to stimulate food intake (Stanley et al. 1986; Stanley, 1993). A role for NPY in the adaptive response to weight loss is suggested by the observation that this NPY pathway (from arcuate nucleus to PVN) is activated by conditions in which animals are unable to consume sufficient energy to meet their ongoing requirements (e.g. starvation, energy restriction, lactation, intense exercise, and uncontrolled diabetes mellitus; Sahu et al. 1988; White \& Kershaw, 1989; Brady et al 1990; Schwartz et al. 1992b, 1993; Sipols et al. 1995). Moreover, consistent with their proposed role as negative feedback signals, both insulin and leptin have been shown to inhibit this hypothalamic NPY pathway. Thus, when animals lose weight, the associated reduction in negative feedback provided to the hypothalamus in the form of insulin and leptin appears to be a signal that activates the 
NPY-containing pathway (Ahima et al. 1996; Schwartz et al. 1996). Increased NPY production and release, in turn, is proposed to contribute to the adaptive increase in food consumption that normally follows weight loss (Fig. 2).

Within the hypothalamus, CRH is expressed primarily in the PVN, and this area is also highly sensitive to the anorectic and thermogenic effects of CRH (Krahn \& Gosnell, 1988; Rothwell, 1989; Bray et al. 1990). Whereas weight loss stimulates NPY, it has the opposite effect on CRH-gene expression in this hypothalamic area (Suemaru et al. 1986; Brady et al. 1990). Moreover, whereas leptin inhibits NPY expression, it stimulates expression of the CRH gene in the PVN (Schwartz et al. 1996). The effect of fasting to lower leptin levels, therefore, may have the dual effect of stimulating NPY and inhibiting CRH (Schwartz et al. 1996). This combination may contribute to both the increase in food intake and the reduction in energy expenditure that promotes the recovery of weight lost by fasting. The balance between the activity of anabolic effector pathways (exemplified by NPY) and that of catabolic effector pathways (exemplified by CRH) may therefore play an important role in determining the state of energy balance that an animal maintains.

\section{IMPLICATIONS FOR WASTING ILLNESS}

The preceding discussion suggests that the ability of weight loss to elicit compensatory responses that promote the recovery of depleted fuel stores depends on the reduction in the level of negative feedback signalling provided by hormones such as insulin and leptin. Importantly, during weight loss, both leptin and insulin levels decrease in the blood and consequently in the brain as well. This initial event is proposed to elicit a cascade of hypothalamic responses that coordinate changes in food intake, energy expenditure, and

Model for the effect of leptin in the CNS control of energy homeostasis

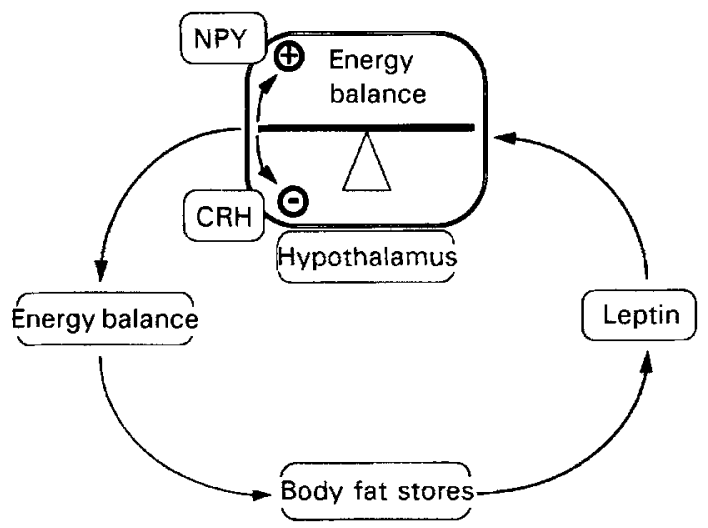

Fig 2. Hypothetical model for integration of negative feedback signals generated in proportion to body adiposity (provided by leptin) with brain pathways that control food intake and energy expenditure. Leptin is secreted by adipocytes, circulates at levels proportional to the amount of energy stored as fat, and enters the brain. Within the hypothalamus, leptin is proposed to inhibit the production and release of NPY and to stimulate that of CRH. Since NPY stimulates food intake, whereas CRH has the opposite effect, the net effect of leptin is to promote anorexia and weight loss by shifting the balance of activity between NPY and CRH pathways in favour of CRH. In this way, a negative feedback loop is created whereby energy restriction lowers body adiposity and hence, leptin levels fall. This, in turn, results in decreased CRH and increased NPY signalling, and therefore reduces energy expenditure and elicits a hyperphagic response. Provided there is access to sufficient amounts of food, energy intake will exceed expenditure until the deficit in fuel stores is corrected. 
the peripheral metabolic milieu to promote increased ingestion and storage of energy until the deficit has been corrected. This model therefore provides a useful framework for investigating the aetiology of wasting illness, since it suggests that the perception by the brain of reduced negative feedback signalling is required to trigger appropriate responses to weight loss. If a disease process were to produce factors that mimic the hypothalamic effects of excess negative feedback signalling from insulin or leptin, therefore, the expected outcome would be sustained anorexia and weight loss that is not accompanied by the usual adaptive response (Schwartz et al. 1995).

What is the evidence that 'leptin like' factors exist and that they are overproduced in conditions associated with wasting? While investigation of this question is just beginning, it is intriguing to note that many cytokines (e.g. tumour necrosis factor- $\alpha$, interleukins- 1,2 and 6 , and interferon- $\gamma$ ) share in common with leptin the ability to increase hypothalamic CRH gene expression and to cause anorexia and weight loss (Sapolsky et al. 1987; Hellerstein et al. 1989; Plata-Salaman, 1991). Since increased cytokine production is associated with certain forms of wasting illness (Grunfeld \& Feingold, 1992), these observations provide a potential mechanism to account for progressive weight loss in such diseases. Thus, cytokines released into the circulation or generated locally within the brain may activate the same CRH pathway that is sensitive to leptin and is proposed to be an important member of the catabolic effector pathway family. Moreover, the leptin receptor is a member of the class-1 cytokine receptor family (Tartaglia et al. 1995), and leptin receptor signalling activates an intracellular signal transduction pathway common to many cytokines (Ghilardi et al. 1996). While elevated leptin levels are unlikely to contribute to anorexic illness (Grunfeld et al. 1996), these observations suggest that cytokines may elicit effects on energy homeostasis that mimic leptin in some regards, and that diseases that increase the hypothalamic action of these inflammatory mediators may contribute to the accompanying anorexia and unopposed weight loss. Based on this hypothesis, a fundamental distinction can be made between weight loss that results from energy restriction and that induced by wasting illness. More specifically, the level of negative feedback signalling in the hypothalamus falls with depletion of fuel stores during energy restriction and, therefore, elicits the appropriate compensatory response. In contrast, weight loss due to the mistaken perception of increased negative feedback signalling provided by cytokines, as proposed during wasting illness, would not be expected to be compensated, since the brain does not get the appropriate signal that fuel stores have been depleted.

\section{SUMMARY AND CONCLUSIONS}

Recent major breakthroughs in our understanding of the negative feedback control of body weight have modified our understanding of disorders characterized by both too much and too little body fat. On the one hand, defective negative feedback signalling in the form of leptin contributes to certain forms of obesity, at least in rodent models. On the other, excessive leptin-like signalling, potentially resulting from the elaboration of inflammatory cytokines, may contribute to the pathogenesis of wasting illness. With the rapid pace of progress that has occurred in this field in recent years, it seems likely that breakthroughs in the treatment of these catastrophic illnesses may follow in the wake of new insights into the physiology and pathophysiology of body weight regulation.

This work was supported by the Career Development and Merit Review Programs of the Department of Veterans Affairs, by the Diabetes Endocrinology Research Center and 
Clinical Nutrition Research Unit at the University of Washington, and by NIH grants \#DK12829 and NS32273.

\section{REFERENCES}

Ahima, R. S., Prabakaran, D., Mantzoros, C., Qu, D., Lowell, B., Maratos-Flier, E. \& Flier, J. (1996). Role of leptin in the neuroendocrine response to fasting. Nature 382, 250-252.

Bagdade, J. D., Bierman, E. L. \& Porte, D. Jr (1967). The significance of basal insulin levels in the evaluation of the insulin response to glucose in diabetic and nondiabetic subjects. Journal of Clinical Investigation 46, 1549-1557.

Brady, L. S., Smith, M. A., Gold, P. W. \& Herkenham, M. (1990). Altered expression of hypothalamic neuropeptide mRNAs in food restricted and food-deprived rats. Neuroendocrinology 52, 441-447.

Bray, G. A., Fisler, J. \& York, D. A. (1990). Neuroendocrine control of the development of obesity: understanding gained from studies of experimental animal models. Frontiers in Neuroendocrinology 11, $128-181$.

Campfield, L. A., Smith, F. J., Gulsez, Y., Devos, R. \& Burn, P. (1995). Mouse OB protein: Evidence for a peripheral signal linking adiposity and central neural networks. Science 269, 546-549.

Chua, S. C., Chung, W. K., Wu-Peng, X. S., Zhang, Y., Liu, S., Tartaglia, L. \& Leibel, R. L. (1996). Phenotypes of mouse diabetes and rat fatty due to mutations in the OB (Leptin) receptor. Science 271, 994-996.

Clark, J. T., Kalra, P. S., Crowley, W. R. \& Kalra, S. P. (1984). Neuropeptide Y and human pancreatic polypeptide stimulate feeding behavior in rats. Endocrinology 115, 427-429.

Coleman, D. L. (1973). Effects of parabiosis of obese with diabetes and normal mice. Diabetologia 9, $294-298$.

Considine, R. V., Sinha, M. K., Heiman, M. L., Kriaucinas, A., Stephens, T. W., Nyce, M. R., Ohannesian, J. P., Marco, C. C., McKee, L. J., Bauer, T. L. \& Caro, J. F. (1996). Serum immunoreactive-leptin concentrations in normal-weight and obese humans. New England Journal of Medicine 334, 292-295.

Drenick, E. J. \& Johnson, D. (1978). Weight reduction by fasting and semistarvation in morbid obesity: longterm follow-up. Intermational Journal of Obesity 2, 123-132.

Frederich, R. C., Lollmann, B., Hamann, A., Napolitano-Rosen, A., Kahn, B. B., Lowell, B. B. \& Flier, J. S. (1995). Expression of $\mathrm{OB} \mathrm{mRNA}$ and its encoded protein in rodents. Journal of Clinical Investigation 96, $1658-1663$.

Garner, D. M. \& Wooley, S. C. (1991). Confronting the failure of behavioral and dietary treatments for obesity. Clinical Psychology Reviews 11, 729-780.

Ghilardi, N., Ziegler, S., Wiestner, A., Stoffel, R. M. H. \& Skoda, R. C. (1996). Defective STAT signaling by the leptin receptor in diabetic mice. Proceedings of the National Academy of Sciences USA 93, 6231-6235.

Grunfeld, C. \& Feingold, K. (1992). Metabolic disturbances and wasting in the acquired immunodeficiency syndrome. New England Journal of Medicine 327, 329-337.

Grunfeld, C., Pang, M., Shigenaga, J., Jensen, P., Lallone, R., Friedman, J. \& Feingold, K. (1996). Serum leptin levels in the acquired immunodeficiency syndrome. Journal of Clinical Endocrinology and Metabolism 81, $4342-4346$.

Halaas, J. L., Gajiwala, K. S., Maffel, M., Cohen, S. L., Chait, B. T., Rabinowitz, D., Lallone, R. L., Burley, S. K. \& Friedman, J. M. (1995). Weight-reducing effects of the plasma protein encoded by the obese gene. Science 269, 543-546.

Hellerstein, M. K., Meydani, S. N., Meydani, M., Wu, K. \& Dinarello, C. A. (1989). Interleukin-1-induced anorexia in the rat. Journal of Clinical Investigation 84, 228-235.

Kaiyala, K. J., Woods, S. C. \& Schwartz, M. W. (1995). A new model for the regulation of energy balance by the central nervous system. American Journal of Clinical Nutrition 62, 1123S-1134S.

Keesey, R. E. \& Powley, T. L. (1986). The regulation of body weight. Annual Review of Psychology 37, 109133.

Kennedy, G. C. (1953). The role of depot fat in the hypothalamic control of food intake in the rat. Proceedings of the Royal Society of London 140B, 579-592.

Krahn, D. D. \& Gosnell, B. A. (1988). Behavioural effects of corticotrophin-releasing factor: localization and characterization of central effects. Brain Research 443, 63-69.

Lee, G., Proenca, R., Montez, J. M., Carroll, K. M., Darvishzadeh, J. G., Lee, J. I. \& Friedman, J. M. (1996). Abnormal splicing of the leptin receptor in diabetic mice. Nature 379, 632-635.

Leibel, R. L., Rosenbaum, M. \& Hirsch, J. (1995). Changes in energy expenditure resulting from altered body weight. New England Journal of Medicine 332, 621-628.

Mercer, J. G., Hoggard, N., Williams, L., Lawrence, C. B., Hannah, L. T. \& Trayhurn, P. (1996). Localization of leptin receptor mRNA and the long form splice variant $(\mathrm{Ob}-\mathrm{Rb})$ in mouse hypothalamus and adjacent brain regions by in situ hybridization. FEBS Letters 387, 113-116.

O’Donohue, T. L., Chronwall, B. M., Pruss, R. M., Mezey, E., Kiss, J. Z., Eiden, L. E., Massari, V. J., Tessel, R. E., Pickel, V. M., DiMaggio, D. A., Hotchkiss, A. J., Crowley, W. R. \& Zukowska-Grojec, Z. (1985). Neuropeptide Y and peptide YY neuronal and endocrine systems. Peptides 6, 755-768. 
Pelleymounter, M. A., Cullen, M. J., Baker, M. B., Hecht, R., Winters, D., Boone, T. \& Collins, F. (1995). Effects of the obese gene product on body weight regulation in ob/ob mice. Science 269, 540-543.

Plata-Salaman, C. R. (1991). Immunoregulators in the nervous system. Neuroscience and Biobehavioral Reviews 15, 185-215.

Rosenbaum, M., Nicholson, M., Hirsch, J., Heymsfield, S. B., Gallagher, D., Chu, F. \& Leibel, R. L. (1996). Effects of gender, body composition, and menopause on plasma concentrations of leptin. Journal of Clinical Endocrinology and Metabolism 81, 3424-3427.

Rothwell, N. (1989). Central effects of CRF on metabolism and energy balance. Neuroscience and Biobehavioral Reviews 14, 263-271.

Sahu, A., Kalra, P. S. \& Kalra, S. P. (1988). Food deprivation and ingestion induce reciprocal changes in neuropeptide $\mathrm{Y}$ concentrations in the paraventricular nucleus. Peptides 9, 83-86.

Sapolsky, R., Rivier, C., Yamamoto, G., Plotsky, P. \& Vale, W. (1987). Interleukin-1 stimulates the secretion of hypothalamic corticotrophin-releasing factor. Science 238, 522-526.

Schwartz, M. W., Dallman, M. F. \& Woods, S. C. (1995). The hypothalamic response to starvation: implications for the study of wasting disorders. American Journal of Physiology 269, R949-R957.

Schwartz, M. W., Figlewicz, D. P., Baskin, D. G., Woods, S. C. \& Porte, D. Jr (1992a). Insulin in the brain: a hormonal regulator of energy balance. Endocrinology Reviews 13, 387-414.

Schwartz, M. W., Seeley, R. J., Campfield, L. A., Burn, P. \& Baskin, D. G. (1996). Identification of targets of leptin action in rat hypothalamus. Journal of Clinical Investigation 98, 1101-1106.

Schwartz, M. W., Sipols, A. J., Grubin, C. E. \& Baskin, D. G. (1993). Differential effect of fasting on hypothalamic expression of genes encoding neuropeptide $\mathrm{Y}$, galanin and glutamic acid decarboxylase. Brain Research Bulletin 31, 361-367.

Schwartz, M. W., Sipols, A. J., Marks, J. L., Sanacora, G., White, J. D., Scheurinck A., Kahn, S. E., Baskin, D. G., Woods, S. C., Figlewicz, D. P. \& Porte, D. Jr (1992b). Inhibition of hypothalamic neuropeptide Y gene expression by insulin. Endocrinology 130, 3608-3616.

Sipols, A. J., Baskin, D. G. \& Schwartz, M. W. (1995). Effect of intracerebroventricular insulin infusion on diabetic hyperphagia and hypothalamic neuropeptide gene expression. Diabetes 44, 147-151.

Stanley, B. G. (1993). Neuropeptide Y in multiple hypothalamic sites controls eating behavior, endocrine, and autonomic systems for energy balance. In The Biology of Neuropeptide Y and Related Peptides, pp. 457-509 [W. F. Colmers and C. Wahlestedt, editors]. Totowa, NJ: Humana Press.

Stanley, B. G., Kyrkouli, S. E., Lampert, S. \& Leibowitz, S. F. (1986). Neuropeptide Y chronically injected into the hypothalamus: A powerful neurochemical inducer of hyperphagia and obesity. Peptides 7, 1189-1192.

Suemaru, S., Hashimoto, K., Hattori, T., Inoue, H., Kageyama, J. \& Ota, Z. (1986). Starvation-induced changes in rat brain corticotrophin-releasing factor (CRF) and pituitary-adrenocortical response. Life Sciences 39, 1161-1166.

Tartaglia, L. A., Dembski, M., Weng, X., Deng, N., Culpepper, J., Devos, R., Richards, G. J., Campfield, L. A., Clark, F. T., Deeds, J., Muir, C., Sanker, S., Moriarty, A., Moore, K. J., Smutko, J. S., Mays, G. G., Woolf, E. A., Monroe, C. A. \& Tepper, R. I. (1995). Identification and expression cloning of a leptin receptor, OB-R. Cell 83, 1263-1271.

White, J. D. \& Kershaw, M. (1989). Increased hypothalamic neuropeptide Y expression following food deprivation. Molecular and Cellular Neuroscience 1, 41-48.

Woods, S. C., Porte, D. J., Bobbioni, E., Ionescu, E., Sauter, J. F., Rohner-Jeanrenaud, F. \& Jeanrenaud, B. (1985). Insulin: its relationship to the central nervous system and to the control of food intake and body weight. American Journal of Clinical Nutriton 42, 1063-1071.

Zarjevski, N., Cusin, I., Vetter, R., Rohner-Jeanrenaud, F. \& Jeanrenaud, B. (1993). Chronic intracerebroventricular neuropeptide-Y administration to normal rats mimics hormonal and metabolic changes of obesity. Endocrinology 133, 1753-1758.

Zhang, Y., Proenca, R., Maffie, M., Barone, M., Leopold, L. \& Friedman, J. M. (1994). Positional cloning of the mouse obese gene and its human homologue. Nature $372,425-432$. 